\title{
On the identity of the common Caligus (Copepoda: Siphonostomatoida: Caligidae) from salmonid netpen systems in southern Chile
}

\author{
Geoffrey A. Boxshall ${ }^{1}$ \& Sandra Bravo ${ }^{2}$ \\ ${ }^{I}$ The Natural History Museum, Cromwell Road, London SW7 SBD, UK, ${ }^{2}$ Universidad Austral de Chile, \\ Puerto Montt Campus, Puerto Montt, Chile
}

Keywords: Crustacea, parasitic Copepoda, salmonid aquaculture, sea líce, Caligus rogercresseyi sp.nov., Chile

\begin{abstract}
The commonest caligid copepod infesting commercial salmonid netpen systems in southern Chile is described as a new species, Caligus rogercresseyi. This species belongs to the macarovigroup of species within the genus. It differs from Caligus flexispina Lewis 1964, with which it has previously been confused, in several important characters. These include the relatively elongate caudal rami, the proportions of the female genital complex and of the male abdomen, and the armature and ornamentation of the antenna in both sexes. The form of the sensillae associated with the postantennal process and the form of the male maxilliped are identified as possible additional diagnostic characters of the macarovi-group.
\end{abstract}

\section{Contents}

Introduction

Methods

Systematics

Discussion

Acknowledgements

References

\section{Introduction}

Salmonid farming commenced in Chile in the early 1980 s. Not long after, the first caligids were reported from cultured salmonids [Coho salmon, Oncorhynchus kisutch (Walbaum)]. These were identified as Caligus teres Wilson, 1905 by Reyes \& Bravo (1983). This was the only species reported from cultured salmonids until 1992 when Gonzalez \& Carvajal (1994) recorded heavy infestations of coho salmon and sea trout [Oncorhynchus mykiss
(Walbaum)] with a second caligid species, identified as Caligus flexispina Lewis 1964. C. flexispina had previously been reported from three different host fishes caught on Easter Island (Fernandez \& Villalba, 1986) and had been included in the key to Chilean Caligus species by Fernandez \& Villalba (1986).

A series of samples collected by one of us (SB) from sea trout in netpen systems around the Puerto Montt region contained a mixture of three copepod species, (two Caligus species and one Lepeophtheirus species), as well as an as yet undescribed new species of the branchiuran genus Argulus. One of the Caligus species was identified as C. teres Wilson, 1905 and it matched closely with the original description (Wilson, 1905), which was based on Chilean material. C. teres was rare in the samples. The other Caligus was the dominant species and is locally referred to as C. flexispina. Although resembling C. flexispina, there were sufficient differences from the type description (Lewis, 1964) based on material from Acanthurid hosts collected in Hawaii, to stimulate further investigation. The type material of Caligus flexispina was examined, on loan from the National Museum of Natural History, Smithsonian Institution, Washington. As a result of these comparisons, the dominant Caligus from commercial salmonid culture systems in Chile is here described as a new species.

\section{Methods}

Material was examined as cleared whole mounts and with appendages dissected and mounted in 
lactophenol using a Leitz Diaplan differential interference contrast microscope.

\section{Systematics}

Caligus rogercresseyi sp. nov. (Figs. 1-5)

Non Caligus flexispina Lewis, 1964

Caligus flexispina: auct.

Material examined. - Type material: Holotype female, four paratype males and five paratype females collected from rainbow trout (Oncorhynchus mykiss) in netpens at Puerto Montt, Chile by one of us (SB). Holotype female, one paratype female and one paratype male stored in collections of National Museum of Natural History, Santiago, Chile. Four paratype females and two paratype males are stored in the collections of The Natural History Museum, London, Reg. Nos. BMNH 1999.737-742.

Other material: Three females $C$. rogercresseyi from Atlantic salmon (Salmo salar, L.) in netpens at Císnes, Chỉle, Reg. Nos BMNH 1999.743-745. One male and one female from sea trout (Salmo Irutta L,) in netpens at Colaco, Chile, 25. May 1998. Collected and presented by Carlos Lobos Blumenfeldt (Aquatic Health Diagnostic \& Research Servíces, Puerto Montt), Reg. Nos BMNH 1999.746-747.

Comparative material of Caligus flexispina: Lewis (1964) designated a female holotype (USNM 105103) and an allotype (USNM 105104) for this material. The material obtained on loan from the USNM comprised 2 vials. Vial 2 contained the male allotype (USNM 105104) and the accompanying data agree with those given in the original description. The other vial (Vial 1) contained a single male (USNM 105105) labelled "Caligus flexispina, 1 immature male, Bet Diamond Head \& Kako Head, Oahu, Hawaii, Sept. 1, 1959. Coll. \& Don. A.Lewis, from the external surface of Acanthurus nigroris. Paratype Acc.No. 231377". On the reverse the label stated "Received July 26, 1960. Appendage slide 13, vial 1,"This male specimen conforms with the description of C. flexispina given by Lewis (1964) but its status as a paratype is doubtful since it was not mentioned in the original material listed by Lewis. The holotype female could not be found.

Description. - Holotype: adult female (Fig. 1A) body length including caudal rami $5.03 \mathrm{~mm}$; paratypes ranging from 4.46 to $5.49 \mathrm{~mm}$, with a mean of $4.96 \mathrm{~mm}$ (based on 6 specimens). Egg strings uniseriate; elongate, up to 1.34 times total body length. Cephalothorax subcircular with marked posterior sinuses; just longer than wide $(2.57 \times$ $2.30 \mathrm{~mm}$ ) and comprising about $50 \%$ of total body length. Free margin of thoracic portion of dorsal cephalothoracic shield extending posterior to rear margins of lateral portions. Genital complex typi- cally just longer than greatest width $(1.75 \times 1.63$ $\mathrm{mm}$ ); mean of 1.06 times longer than maximum width; slightly produced posterolaterally to form short rounded lobes in mature and ovigerous specimens (Fig. 1A). Abdomen 1-segmented; about 1.4 times longer than wide $(0.51 \times 0.37 \mathrm{~mm})$; carrying paired caudal rami obliquely on distal margin; anus terminal. Abdominal surface ornamented with scattered sensillae on lateral and ventral surfaces as illustrated (Fig. 1B).

Caudal rami with parallel sides, 1.33 to 1.50 times longer than wide, measured at midpoints of margins (Fig. 1B). Each ramus armed with 3 long plumose setae on distal margin, short hirsute seta at inner distal angle, slightly longer hirsute seta at outer distal angle and minute hirsute seta located just ventral to outer distal seta. Inner margin of ramus ornamented with row of fine pinnules distally. Single sensilla present on ventral and dorsal surfaces.

Antennule typical for family; 2-segmented; large proximal segment with 25 plumose setae along anteroventral margin and 2 setae located dorsally; distal segment bearing 13 elements (11 setae plus 2 aesthetascs) clustered around apex plus isolated seta on posterior margin. Antenna (Fig. 1C) with posteriorly directed spinous process on proximal segment; middle segment subrectangular, tapering slightly distally, unarmed; terminal segment forming strong, recurved claw armed with slender seta midway along anterior margin and with minute seta on raised collar-like structure located proximally on ventral surface (see inset detail on Fig. 1C). Postantennal process (Fig. 1D) forming slender recurved claw; ornamented with 2 simple sensillae on basal part and with similar simple sensilla on adjacent ventral cephalic surface. Mandible of typical stylet-like structure with 12 marginal teeth. Maxillule (Fig. 2A) comprising anterior papilla bearing 3 unequal, naked setae and posterior tinelike process. Maxilla 2-segmented (Fig. 2B,C), comprising elongate syncoxa and basis: basis bearing subapical flabellum on anterior margin; posterior margin finely rugose distally (Fig. 2C); terminating in two unequal claw-like elements (calamus and canna). Calamus about twice as long as canna, both ornamented with strips of serrated membrane arranged obliquely along surface. Maxilliped 


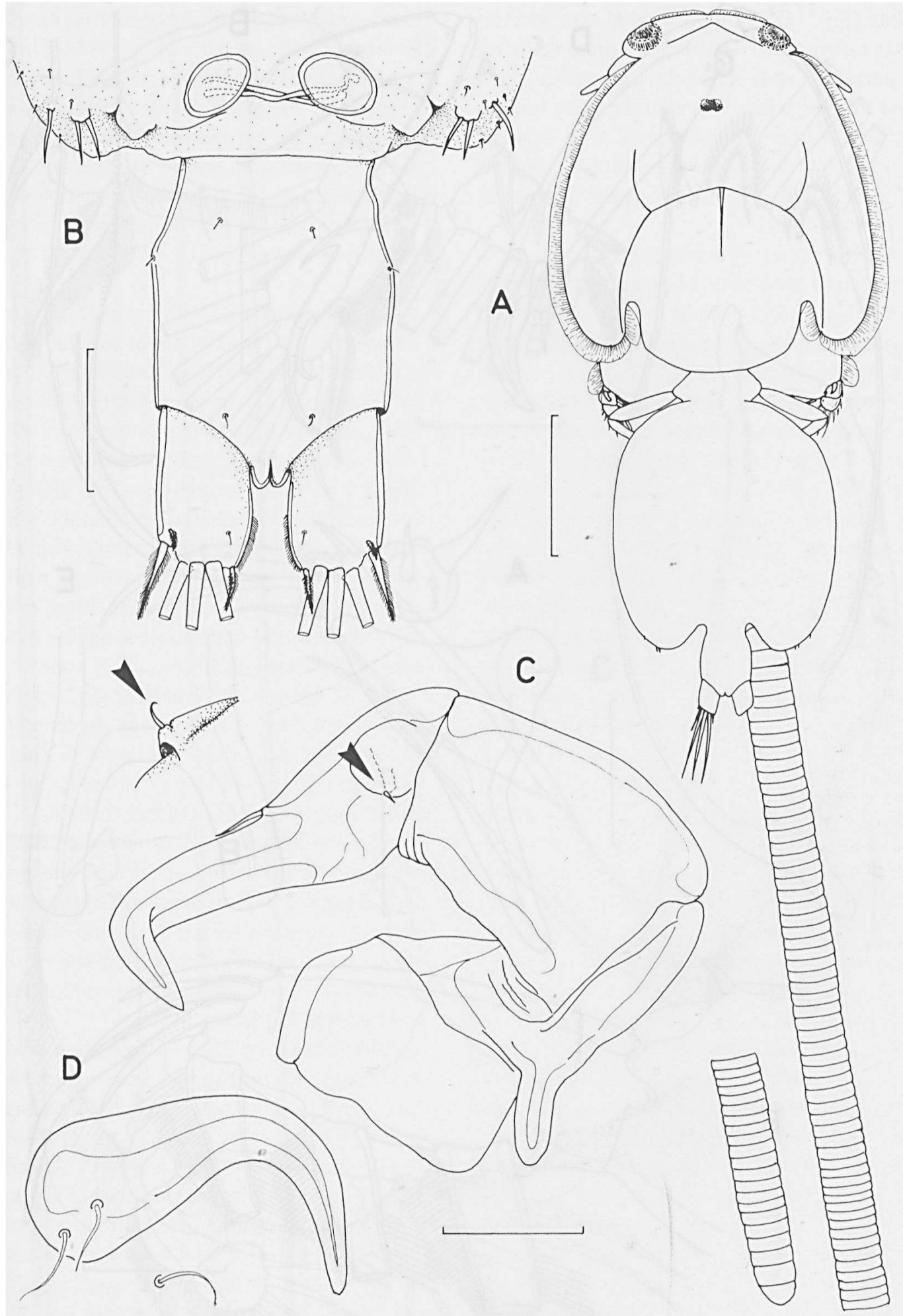

Fig. 1. Caligus rogercresseyi n. sp. Female. A, Holotype, dorsal; B, Posterior margin of genital complex and abdomen, ventral view showing fifth legs and attached spermatophores; C, Antenna, ventral view with arrowed inset showing detail of collar-like structure bearing minute seta; D, Postantennal process, ventral view showing simple sensillae. Scale bars $A=1 \mathrm{~mm}, \mathrm{~B}=200 \mathrm{~mm}$, $\mathrm{C}, \mathrm{D}=100 \mathrm{~mm}$. 


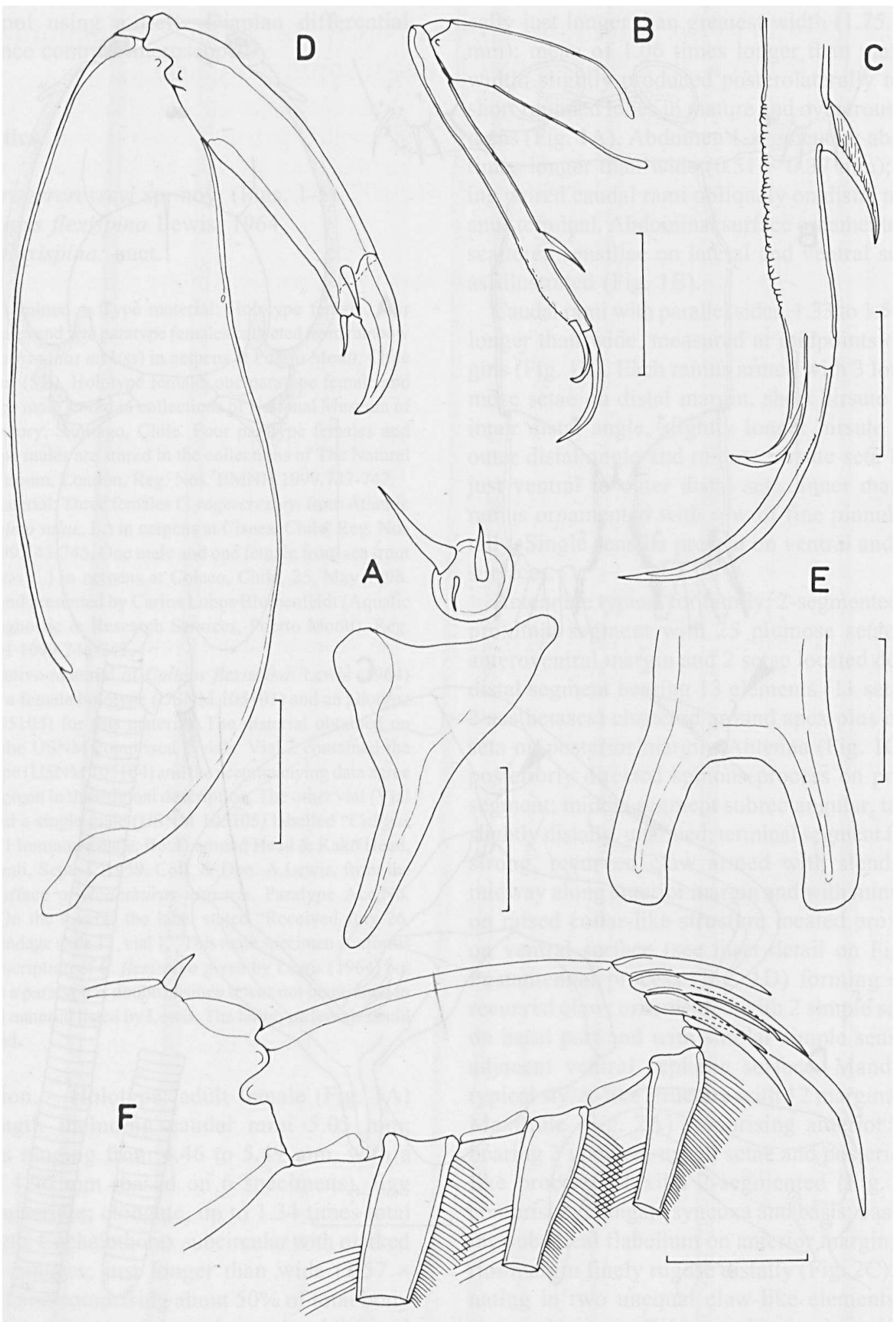

Fig. 2. Caligus rogercresseyi n. sp. Female. A, Maxillule, ventral; B, Maxilla, ventral; C, Tip of maxilla showing rugose posterior margin; D, Maxilliped; E, Sternal furca; F, Distal segment of exopod of first leg, ventral view showing spines 1 to 4 . Scale bars $A, C-E=100 \mathrm{~mm}, B=200 \mathrm{~mm}, F=50 \mathrm{~mm}$. 


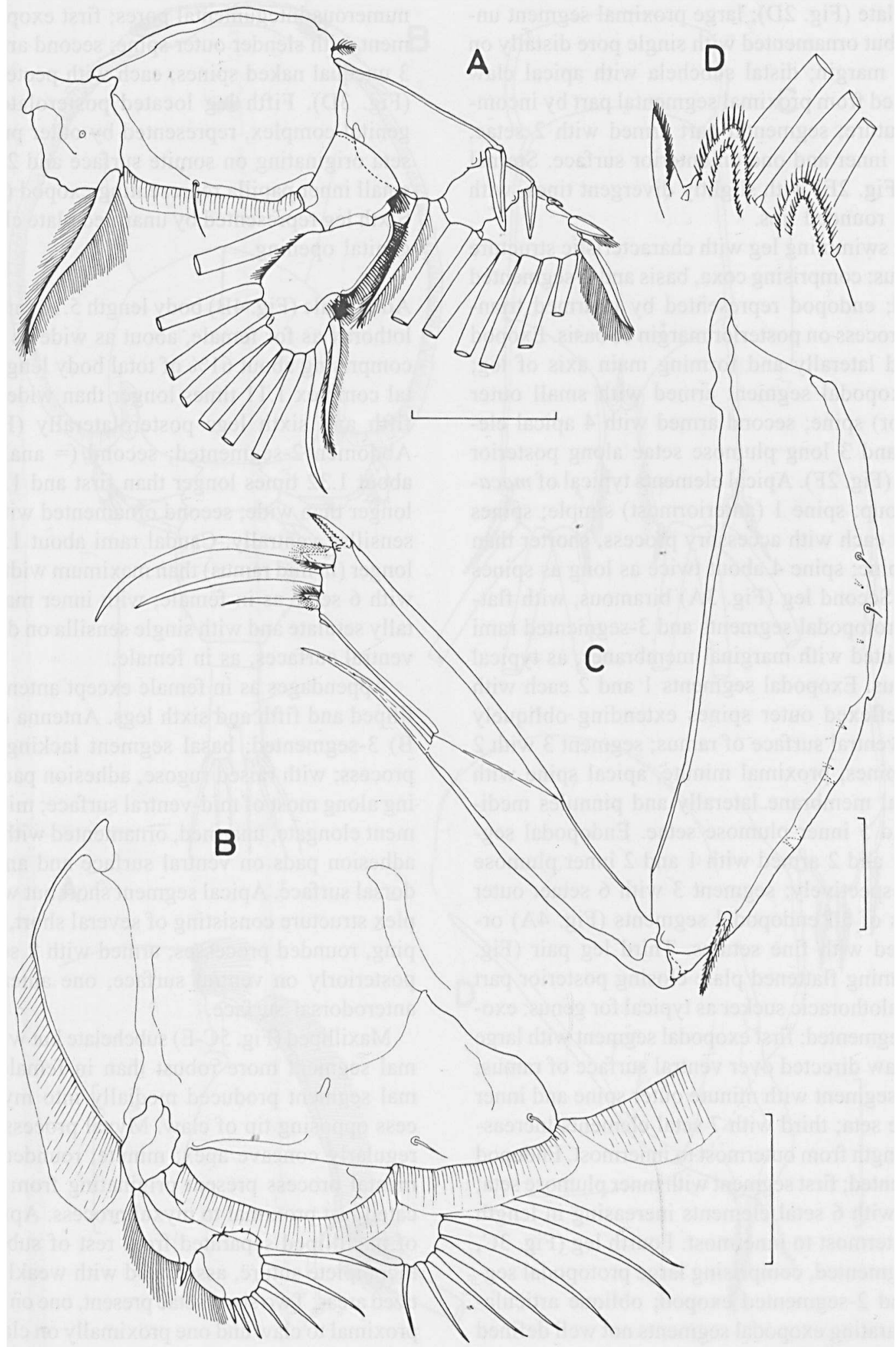

Fig. 3. Caligus rogercresseyi n. sp. Female. A, Second leg, ventral; B, Third leg, ventral; C, Fourth leg, ventral; D, Tip of fourth leg showing pectens. Scale bars $=200 \mathrm{~mm}$. 
subchelate (Fig. 2D); large proximal segment unarmed but ornamented with single pore distally on medial margin; distal subchela with apical claw separated from proximal segmental part by incomplete suture; segmental part armed with 2 setae, one on inner and one on anterior surface. Sternal furca (Fig. 2E) with slightly divergent tines, with bluntly rounded tips.

First swimming leg with characteristic structure for genus: comprising coxa, basis and 2-segmented exopod; endopod represented by unarmed triangular process on posterior margin of basis. Exopod directed laterally and forming main axis of leg; first exopodal segment armed with small outer (anterior) spine; second armed with 4 apical elements and 3 long plumose setae along posterior margin (Fig. 2F). Apical elements typical of macarovi-group: spine 1 (anteriormost) simple; spines 2 and 3 each with accessory process, shorter than main spine; spine 4 about twice as long as spines 1 to 3. Second leg (Fig. 3A) biramous, with flattened protopodal segments and 3-segmented rami ornamented with marginal membranes, as typical for genus. Exopodal segments 1 and 2 each with large reflexed outer spines extending obliquely across ventral surface of ramus; segment 3 with 2 outer spines, proximal minute, apical spine with marginal membrane laterally and pinnules medially, and 5 inner plumose setae. Endopodal segments 1 and 2 armed with 1 and 2 inner plumose setae respectively; segment 3 with 6 setae: outer margins of all endopodal segments (Fig. 4A) ornamented with fine setules. Third leg pair (Fig. 3B) forming flattened plate closing posterior part of cephalothoracic sucker as typical for genus: exopod 3-segmented; first exopodal segment with large outer claw directed over ventral surface of ramus; second segment with minute outer spine and inner plumose seta; third with 7 setal elements increasing in length from outermost to innermost. Endopod 2-segmented; first segment with inner plumose seta; second with 6 setal elements increasing in length from outermost to innermost. Fourth leg (Fig. 3C, D) 3-segmented, comprising large protopodal segment and 2-segmented exopod; oblique articulation separating exopodal segments not well defined on ventral surface: protopodal segment armed with outer seta and ornamented with 2 sensillae plus numerous integumental pores; first exopodal segment with slender outer spine; second armed with 3 unequal naked spines, each with pecten at base (Fig. 3D). Fifth leg located posterolaterally on genital complex, represented by outer protopodal seta originating on somite surface and 2 setae on small inner papilla representing exopod (Fig. 1B). Sixth leg represented by unarmed plate closing off genital opening.

Adult male (Fig. 4B) body length $5.16 \mathrm{~mm}$; cephalothorax as for female, about as wide as long and comprising about $61 \%$ of total body length. Genital complex 1.11 times longer than wide; bearing fifth and sixth legs posterolaterally (Fig. 4D). Abdomen 2-segmented; second ( $=$ anal) somite about 1.32 times longer than first and 1.28 times longer than wide; second ornamented with pair of sensillae ventrally. Caudal rami about 1.78 times longer (in mid ramus) than maximum width; armed with 6 setae as in female; with inner margin distally setulate and with single sensilla on dorsal and ventral surfaces, as in female.

Appendages as in female except antenna, maxilliped and fifth and sixth legs. Antenna (Fig. 5A, B) 3-segmented; basal segment lacking spinous process; with raised rugose, adhesion pad extending along most of mid-ventral surface; middle segment elongate, unarmed, ornamented with 2 raised adhesion pads on ventral surface and another on dorsal surface. Apical segment short but with complex structure consisting of several short, overlapping, rounded processes; armed with 2 setae, one posteriorly on ventral surface, one anteriorly on anterodorsal surface.

Maxilliped (Fig. 5C-E) subchelate but with proximal segment more robust than in female; proximal segment produced medially into myxal process opposing tip of claw. Myxal process with irregularly concave apex; minute, rounded integumental process present originating from pore located just proximal to myxal process. Apical claw of maxilliped separated from rest of subchela by incomplete suture, associated with weakly sclerotized areas. Two short setae present, one on subchela proximal to claw and one proximally on claw. Inner margin of claw with irregular flange producing close fit with myxal process when adducted. 


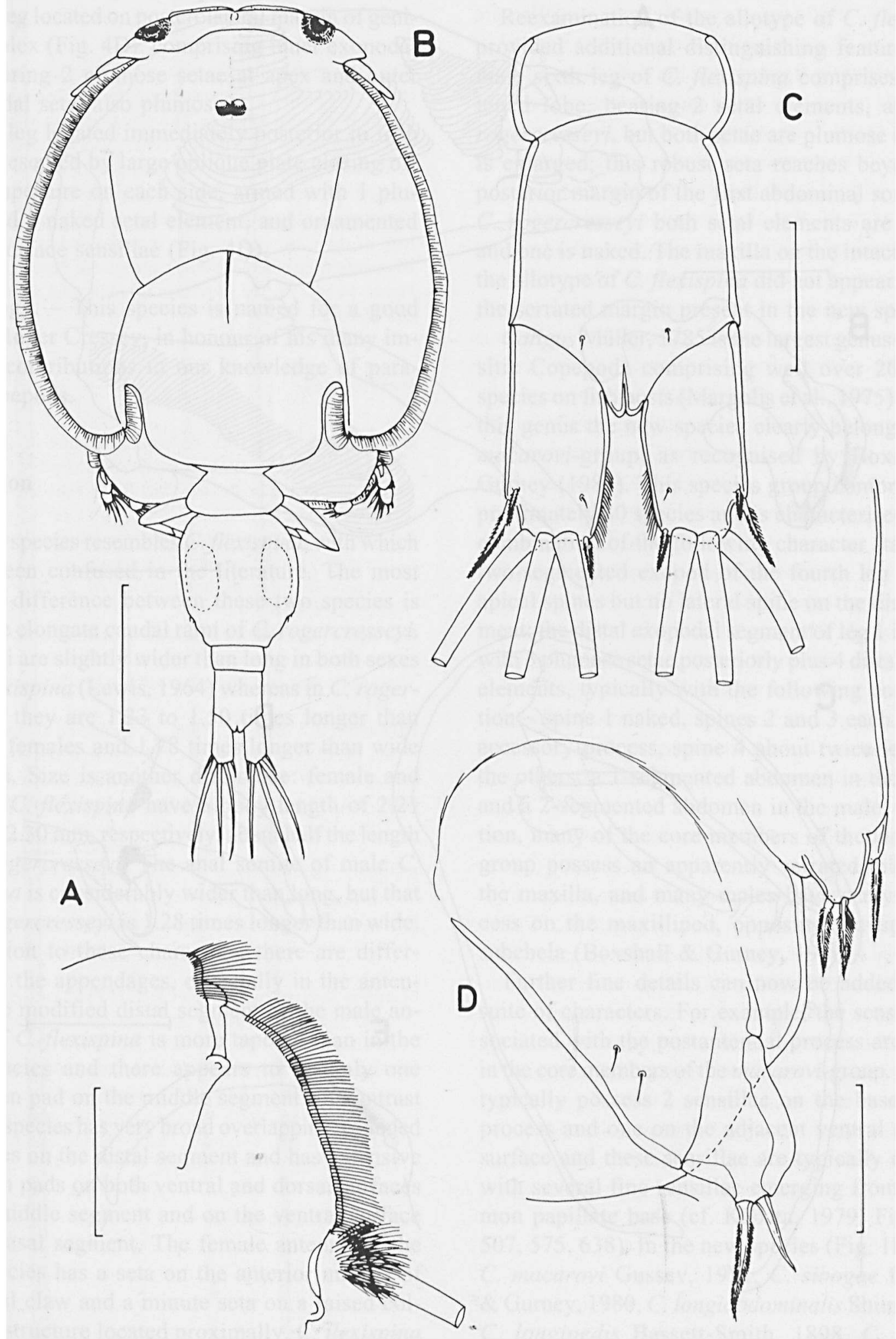

Fig. 4. Caligus rogercresseyi $\mathrm{n}$. sp. A, Female, outer margin of endopodal segments of second leg; B, Male, dorsal; C, Abdomen, ventral; $D$, Fifth and sixth legs on left side, ventral view. Scale bars $A=100 \mathrm{~mm}, B=1 \mathrm{~mm}, C=250 \mathrm{~mm}, D=100 \mathrm{~mm}$. 


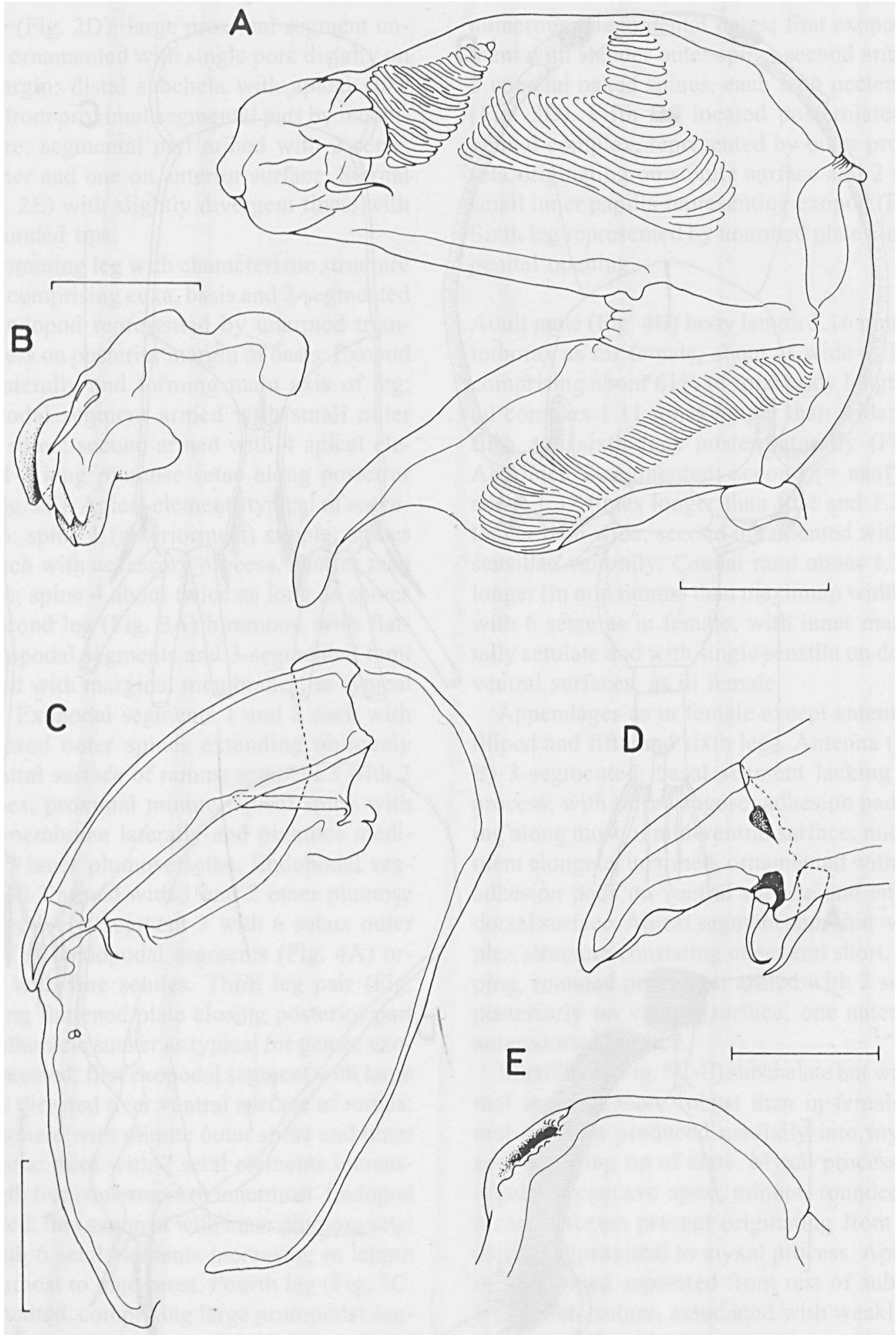

Fig. 5. Caligus rogercresseyi n. sp. Male. A, Antenna, ventral view showing adhesion pads; B, Distal segment of antenna, anterior view; C, Maxilliped, anterior view; D, Claw at tip of maxilliped subchela; posterior view; E, Myxal process, posterior. All scale bars $=100 \mathrm{~mm}$. 
Fifth leg located on posterolateral margin of genital complex (Fig. 4D), comprising inner exopodal lobe bearing 2 plumose setae at apex and outer protopodal seta, also plumose.

Sixth leg located immediately posterior to fifth leg: represented by large oblique plate closing off genital aperture on each side, armed with 1 plumose and 1 naked setal element, and ornamented with 2 surface sensillae (Fig. 4D).

Etymology. - This species is named for a good friend, Roger Cressey, in honour of his many important contributions to our knowledge of parasitic copepods.

\section{Discussion}

The new species resembles $C$. flexispina, with which it has been confused in the literature. The most obvious difference between these two species is the more elongate caudal rami of $C$. rogercresseyi. The rami are slightly wider than long in both sexes of C. flexispina (Lewis, 1964) whereas in C. rogercresseyi they are 1.33 to 1.50 times longer than wide in females and 1.78 times longer than wide in males. Size is another difference: female and male of C. flexispina have a body length of 2.21 $\mathrm{mm}$ and $2.30 \mathrm{~mm}$, respectively, about half the length of $C$. rogercresseyi. The anal somite of male $C$. flexispina is considerably wider than long, but that of $C$. rogercresseyi is 1.28 times longer than wide. In addition to these characters, there are differences in the appendages, especially in the antennae. The modified distal segment of the male antenna of $C$. flexispina is more tapered than in the new species and there appears to be only one adhersion pad on the middle segment. In contrast the new species has very broad overlapping, rounded processes on the distal segment and has extensive adhesion pads on both ventral and dorsal surfaces of the middle segment and on the ventral surface of the basal segment. The female antenna of the new species has a seta on the anterior margin of the distal claw and a minute seta on a raised collar-like structure located proximally. C. flexispina apparently has only one seta, located proximally on the distal claw (Lewis, 1964).
Reexamination of the allotype of C. flexispina provided additional distinguishing features. The male sixth leg of $C$. flexispina comprises a flattened lobe, bearing 2 setal elements, as in $C$. rogercresseyi, but both setae are plumose and one is enlarged; this robust seta reaches beyond the posterior margin of the first abdominal somite. In C. rogercresseyi both setal elements are shorter and one is naked. The maxilla on the intact side of the allotype of C. flexispina did not appear to have the serrated margin present in the new species.

Caligus Müller, 1785 is the largest genus of parasitic Copepoda comprising well over 200 valid species on fish hosts (Margolis et al., 1975). Within this genus the new species clearly belongs to the macarovi-group, as recognised by Boxshall \& Gurney (1980). This species group comprises approximately 30 species and is characterised by the combination of the following character states: the two-segmented exopod of the fourth leg bears 3 apical spines but no lateral spine on the distal segment; the distal exopodal segment of leg 1 is armed with 3 plumose setae posteriorly plus 4 distal margin elements, typically with the following configuration - spine 1 naked, spines 2 and 3 each with an accessory process, spine 4 about twice length of the others; a 1-segmented abdomen in the female and a 2-segmented abdomen in the male. In addition, many of the core members of the macarovigroup possess an apparently serrated margin on the maxilla, and many males have a myxal process on the maxilliped, opposing the tip of the subchela (Boxshall \& Gurney, 1980).

Further fine details can now be added to this suite of characters. For example, the sensillae associated with the postantennal process are simple in the core members of the macarovi-group. Caligids typically possess 2 sensillae on the base of this process and one on the adjacent ventral cephalic surface and these sensillae are typically complex with several fine sensillae emerging from a common papillate base (cf. Kabata, 1979: Figs. 503, $507,575,638$ ). In the new species (Fig. 1D), as in C. macarovi Gussev, 1951, C. sibogae Boxshall \& Gurney, 1980, C. longiabdominalis Shïno, 1965, C. longipedis Bassett-Smith, 1898, C. rugosus Shiino, 1959, C. klawei Shiino, 1959, C. tenuicaudatus Shiino, 1959 and C. antennatus Boxshall 
\& Gurney, 1980 (for example), these sensillae are all simple. These sensillae are often not figured or are inaccurately figured, and the distribution of this character across the entire macarovi-group should be confirmed. The allotype of $C$. flexispina, for example, was shown as having multiple sensillae (Lewis, 1964: fig 4l) but examination of the specimen confirmed that the sensillae were simple.

The form of the male maxilliped is also unusual in members of the macarovi-group. The adduction mechanism for the subchela involves a rigid, sclerotised bar-like structure which expands to form a plate-like surface for insertion of the powerful adductor muscles within the robust basal segment. The fibres of the adductor muscles inserting on this plate-like surface have a partly pinnate arrangement (see Boxshall, 1990). Contraction of these adductors indirectly closes the subchela against the myxal process, via the rigid bar. Other members of the macarovi-group that possess this bar include C. oviceps Shiino, 1952, C. flexispina and C.sibogae. Males are unknown in several species and in others the male maxillipeds have been figured from particular angles that make verification of this character difficult. As for the sensillae discussed above, the distribution of this character across the entire macarovi-group should be confirmed.

The natural hosts of $C$. rogercresseyi sp. nov. (as $C$. flexispina) were recently identified by Carvajal et al. (1998) as the "Robalo" (Eleginops maclovinus Cuvier, in Cuvier \& Valenciennes), the "Pejerrey" (Odontesthes regia Humboldt, in Humboldt \& Valenciennes) and Paralicthys microps Günther, belonging to the families Nototheniidae, Atheriniidae and Paralichthyidae respectively. The natural occurrence of $C$. rogercresseyi on three distantlyrelated host families indicates a low degree of host specificity, an inference supported by the parasite's relatively rapid exploitation of the new salmonid hosts introduced into the region of southern Chile.

\section{Acknowledgements}

This collaborative study arose out of an extended scientific study visit to Chile supported initially by Operation Raleigh and by British Airways plc. The visit to Puerto Montt by GAB was supported by the British Council. The authors are grateful to all these organizations and companies for their substantial support of this study. We are grateful to T. Chad Walter (Smithsonian Institution, Washington D.C.) for arranging the loan of the Caligus flexispina material and to Carlos Lobos Blumenfeldt (Aquatic Health Diagnostic \& Research Services, Puerto Montt) for the provision of additional material of the new species.

\section{References}

Boxshall GA. 1990. The skeletomusculature of siphonostomatoid copepods, with an analysis of adaptive radiation in structure of the oral cone. Phil. Trans. Roy. Soc. Lond. Ser. B. 328: 167-212.

Boxshall GA, Gurney AR. 1980. Descriptions of two new and one poorly known species of the genus Caligus Müller, 1785 (Copepoda: Siphonostomatoida), Bull. Br. Mus. nat. Hist. (Zool.) 39: 161-178.

Carvajal J, González L, George-Nascimento M. 1998. Native sea lice (Copepoda: Caligidae) infestation of salmonids reared in netpen systems in southern Chile. Aquaculture 66: 241-246.

Fernandez J, Villalba C. 1986. Contribucion al conocimiento del genero Caligus Muller, 1785 (Copepodax Síphonostomatoida) en Chile. Gayana (Zool.) 50:37-62.

González L, Carvajal J. 1994. Parásitos en los cultívos marinos de salmónidos en el sur de Chỉle. Invest. Pesq. (Chile) 38: 87-96.

Kabata Z. 1979. Parasitic Copepoda of British fishes. London The Ray Society, 1-468.

Lewis AG. 1964. Caligoid copepods (Crustacea) of the Hawaiian Islands: Parasitic on fishes of the family Acanthuridae. Proc. U.S. Nat. Mus. 115: 137-244.

Margolis L, Kabata Z, Parker RR. 1975. Catalogue and synopsis of Caligus, a genus of Copepoda (Crustacea) parasitic on fishes. Bull. Fish. Res. Bd. Can. 192*1-117.

Reyes X, Bravo S. 1983. Nota sobre una copepodosis en salmones de cultivo. Invest. Mar. Valparaiso 11: 55-57.

Wilson CB. 1905. North American parasitic copepods belonging to the family Caligidae, Part I. The Caliginae. Proc. U.S. Nat. Mus. 28: 479-672, pls 5-29.

Received: 27 April 1999 